DOI https://doi.org/10.18551/rjoas.2017-06.03

\title{
DO GOVERNMENTAL INCENTIVES PROMOTE PARTNERSHIPS AMONG AGRICULTURAL FIRMS? A MULTIPLE CASE STUDY FROM ITALY
}

\author{
Brusati Luca*, PhD, Associate Professor \\ lacuzzi Silvia, PhD, Contract Researcher \\ Ianniello Mario, $\mathrm{PhD}$, Instructor \\ Udine University, Udine, Italy \\ *E-mail: brusati@uniud.it
}

\begin{abstract}
The paper analyses a sample of successful multi-stakeholder projects co-financed by the European Agricultural Fund for Rural Development in Friuli Venezia Giulia Autonomous Region (Italy) to understand what factors allow governmental incentives to trigger more effective partnerships among agricultural firms. Our analysis, based on the standardized approach for the benchmarking of rural development initiatives designed by the Assembly of European Regions, identified six predictors of success. Three are associated to the contents of the project, i.e., strategic vision, sustainability over time and market orientation; two are linked to the nature of the partnership, i.e., critical mass and project leaders' entrepreneurship; one more seems to be associated with policy design rather than implementation, i.e., the design of funding requirements specifically targeted to address critical weaknesses in agricultural development. Thanks to a better understanding of these predictors of success, policy-makers promoting rural development can improve the costeffectiveness of incentive schemes, in particular by setting tighter standards to be met by agricultural firms wishing to access preferential funding.
\end{abstract}

\section{KEY WORDS}

Partnership, agriculture, incentives, good practice, European Union.

Rural development is undoubtedly a key area for governmental intervention, in the European Union (EU) as well as in the Russian Federation [1, 2, 3]. The economic viability of farming and forestry remains central to rural economies; at the same time, related issues such as environmental protection, climate change, biodiversity, water supply and food security are becoming increasingly important dimensions of the modern concept of sustainability.

In order to coordinate intervention strategies in the area of rural development across the Member States, in 1962 the EU established a Common Agricultural Policy (CAP), which underwent several changes over the years but is still the largest single item of expenditure in the EU budget, accounting for $39 \%$ of the total in 2015 [4]. Pursuant to European Commission Regulation No. 1698/2005, which provides the framework regulations underpinning the CAP, EU policies pursue three objectives: increase the competitiveness of agriculture, farming and forestry through restructuring, development and innovation; enhance the environment by supporting territorial management; improve the quality of life in rural areas and promote the diversification of economic activities.

As in the Russian Federation [5, 6], also in the EU dedicated governmental subsidies are available through the CAP to improve the competitiveness of agriculture, farming and forestry, especially in order to support capital expenditure [7]. In the case of the EU such support is primarily channelled through the European Agricultural Fund for Rural Development (EAFRD), overseen by the European Commission's Directorate General for Agriculture and Rural Development. EAFRD supports the implementation of Rural Development Programmes (RDPs) across the EU, agreed with and co-financed by national and regional governments along standardized guidelines to tackle the specific challenges of development in different local contexts. 
The promotion of partnerships in agriculture is a recurring theme in the debate about rural development: in many EU Member States the small average size of farms and agroindustrial businesses implies that they lack scale economies, negotiation power and innovation potential, and thus the competitiveness needed today to operate effectively on the market. Partnerships help address the constraints small producers face in scaling up, including high transaction costs and lack of information [8]. We use here the broader term "partnership" rather than the term "cooperation" because we do not refer exclusively to the establishment of farmers' consortia, cooperatives and associations, but to all the multistakeholder arrangements that can trigger complementarity and synergies among different players, and especially with other market participants along agricultural value chains.

The aim of our study is to understand the factors underpinning successful partnerships in agriculture, based on an in-depth analysis of "good practices" co-financed by the 20072013 RDP of Friuli Venezia Giulia Autonomous Region in Italy. Friuli Venezia Giulia is located in the northeast of Italy, bordering Veneto Region, Austria, Slovenia and the Adriatic Sea: it covers a total area of $7,858 \mathrm{~km}^{2}$ and has a population of 1.2 million people. The region is mostly rural; Utilised Agricultural Area (UAA) covers $28 \%$ of the territory and is mainly used for arable crops and pasture, whereas forests cover $41 \%$ of the territory and tend to expand due to the abandonment of agriculture, driven in turn by the fact that $23 \%$ of UAA is in mountain areas. Agriculture employs $3.26 \%$ of total employed people and generates $1.2 \%$ of the total added value of the region. Farm structure is fragmented: 22,320 agricultural firms operate in the region, with an average size of 10 hectares. $62 \%$ of farm holders practice agricultures only part-time, and only $4 \%$ of them have a high school degree in agronomics [9].

The Regional Government of Friuli Venezia Giulia is keenly aware of the need to improve the competitiveness of the agricultural sector, and promoting more effective and more sustainable partnerships is an important target goal in its RDPs: the 2007-2013 RDP of Friuli Venezia Giulia stated explicitly that "an increasing autonomy from public transfers and a growing competitive capacity can be the result of a strong orientation towards quality, efficiency, innovation, environmental compatibility and the development of forms of cooperation and integration that can bring producers to the market" $[10, p$. 131]. On the backdrop of this vision the unit of the Regional Administration responsible for rural development commissioned this study, based on the assumption that more systematic evidence on what makes partnerships successful is important not only for market players, but also for the policy-makers in charge for the design and implementation of governmental programmes supporting agriculture.

\section{METHODOLOGY OF RESEARCH}

To understand the factors underpinning successful partnerships in agriculture we chose to use a qualitative methodology, more suitable to help identify commonalities in the heterogeneous set of the projects co-financed by the 2007-2013 RDP of Friuli Venezia Giulia. More specifically we analyzed a series of six "good practices" as a multiple case study [11]. To identify good practices, in agreement with the unit of the Regional Administration responsible for rural development we took three requirements into account:

- first of all, to be assessed in a reliable way projects had to be already concluded, or at least nearing conclusion (minimum $80 \%$ of planned expenditure already accounted for);

- secondly, they had to stand out for the results they achieved, in terms of impact, costbenefit ratio, innovative partnership or working methods;

- the last criterion was a balanced distribution of good practices among the different lines of intervention (so-called "axes" and "measures") co-financed by the 2007-2013 RDP of Friuli Venezia Giulia.

The following six projects were selected as good practices: integrated territorial project "Urban agriculture" (support to farms located in the territory of Udine, the second largest town in Friuli Venezia Giulia); integrated value chain project "Fantinel Pitars" (improved coordination of supply chain for more effective marketing of wine products); integrated value 
chain project "Venchiaredo" (improved coordination of supply chain for more effective marketing of cheese products); agricultural collective action "Vigna in Collio" (upgrading of equipment among the wineries in the Collio area); forestry collective action "Certified poplar plantation in Friuli Venezia Giulia" (certification of environmental sustainability of poplar plantations); forestry collective action "Ovaro, Rigolato, Prato Carnico, Comeglians amd Paluzza Municipalities" (support to the refurbishment of old wooden buildings in mountain areas according to traditional architectural standards).

The sample of projects we selected guaranteed a balanced distribution among the lines of intervention funded by the 2007-2013 RDP of Friuli Venezia Giulia: half of them are "integrated projects" in the EAFRD terminology, i.e. territorial or value chain partnerships, and half are "collective actions", i.e. partnerships among direct competitors. Four projects concern agriculture, whereas two deal with forestry; integrated forestry projects could not be included, since, by the time of our study was carried out, none of them had come to conclusion or to the expenditure threshold we set.

Our analysis was based on the project documents made available to the Regional Administration by each project leader and summarized in a data acquisition form. For this purpose we adopted the standard template used by the Assembly of European Regions in the framework of the RUR@CT network to facilitate the transfer and benchmarking of good practices in rural development across the EU [12]. Project document data were triangulated with semi-structured interviews with project leaders and other key informants to better appreciate the factors, especially in terms of design and dynamics that made it possible for expected results to be achieved, and for partnerships to prove successful. Whenever possible two researchers were involved in the interviews to reduce the risk of subjective interpretation of answers; the completed data acquisition form was then validated by project leaders and other interviewees.

\section{RESULTS AND DISCUSSION}

Our study allowed the identification of six commonalities shared by the projects qualifying as good practices. Three predictors of success are associated to the contents of the project, i.e., strategic vision, sustainability over time and market orientation.

- Strategic vision. Projects seem to be more effective if they explicitly aim further than securing financial contributions, and if they focus on strategic goals (medium to long-term) rather than merely tactical (short-term) ones, not only in the design phase, but also in the implementation of project activities. In the most forward-looking cases, support for the projects' strategic objectives became a discriminating criterion for joining the partnership, also because in some cases project participation requires partners to behave according to predetermined conditions, not only in terms of the advanced investment on which financial support is calculated, but also of compliance with certain production guidelines.

- Sustainability over time. As widely acknowledged in the project management literature, successful projects extend beyond the original planning horizon, although sometimes in partially different formats. Sustainability over time is directly related to the ability to operate pursuing a strategic vision. Moreover, the sustainability of a partnership beyond its formal deadline can be a proxy indicator of the fact that the project has been designed to address a real need, rather than just to exploit a funding opportunity. In these cases partnerships continue to exist over time, even though some of their members may change, and use available financing opportunities to achieve their goals. In many cases, therefore, one of the most important achievements of the projects we identified as good practices is testing or consolidating this kind of long-term relationships.

- Market orientation. For the lines of intervention for which access to end consumers is important, strategic vision and sustainability over time also mean the pursuit of a market positioning that provides beneficiaries a sustainable competitive advantage. This is especially relevant for integrated value chain projects, but not only: also collective actions at times display this feature. When governmental contributions just help bear the burden associated with capital expenditure, competitive implications are negligible. When financial 
support funds investments that help lower operating costs, the implications in terms of market positioning and competitive advantage are undoubtedly more relevant. The most ambitious projects go further, aiming to widen the margin between prices and costs to the benefit of all partners through activities that pursue primarily an increase in market value based on product differentiation [13], for instance through certification of environmental sustainability or improved traceability of the supply chain. ${ }^{1}$

Two more predictors of success seem to be linked to the nature of the partnership, i.e., critical mass and project leaders' entrepreneurship.

- Critical mass. Taking into account the small average size of agricultural, farming and forestry firms in Friuli Venezia Giulia, patchy initiatives are likely to have a limited impact, while projects that set up partnerships among multiple stakeholders working in the same direction and pursuing at least partially shared goals tend to be more effective. In this perspective, integrated territorial projects and integrated value chain projects seem more promising than collective actions; while integrated projects are explicitly aimed at facilitating cooperation among entities from the same geographic area or belonging to two or more segments of the same supply chain, collective actions tend to finance actions carried out in parallel by firms and institutions that keep operating autonomously, failing, at least in some cases, to catalyse the development of real synergies.

- Project leaders' entrepreneurship. Most of the projects selected as good practices are coordinated by leaders who stand out for their entrepreneurship: they do not stop at facilitating the obtainment by all partners of the financial contributions made available through the EAFRD, but actively seek to establish and maintain a true partnership. Not surprisingly, they tend to match the profile of "policy entrepreneurs" suggested by Kingdon [15]. As a consequence, it is not enough for project leaders to have the formal requirements and skills necessary to submit applications and manage bureaucratic procedures: they also need substantial (not necessarily hierarchical) transformational leadership vis-à-vis other project participants, based on a deeply-seated commitment to making the partnership work in order to achieve individual goals.

One final commonality shared by the projects identified as good practices seems to be linked to policy design rather than implementation: successful partnerships are consistently associated with lines of intervention where funding requirements were specifically designed to address critical weaknesses in agricultural development. For each line of intervention, RDPs establish that applications have better chances of success and financial support corresponds to a higher share of expenditure provided that partnerships or proposed project activities meet certain requirements. This is a very effective feature, which leads applicants to design partnerships and activities in such a way to fully meet these requirements, in keeping with the logic of nudging as a driver of success in modern governmental policies [16]. Obviously partners' commitment is not always genuine, and in many cases it is merely a matter of box ticking. On the other hand, one must remember that regional governments set these requirements based on a detailed analysis of the critical challenges to rural development in each area of intervention. The good practices we analyzed suggest that providing preferential support to projects allowing partners to test innovative, targeted solutions to these challenges leads to interesting results. One likely driver of success seems to be that the availability of preferential funding supports the agenda of "policy entrepreneurs" who in many cases are already striving to trigger change among their peers: it is not surprising that some interviewees suggest that preferential funding for fully compliant projects should be even more prominent.

Given the intrinsic limitations of a multiple case study, the good practices we studied are not expected to represent systematically all the projects funded by the 2007-2013 RDP of Friuli Venezia Giulia, nor was the analysis designed as a fully-fledged final evaluation, i.e. with the

\footnotetext{
1 According to the classical taxonomy of competitive strategies suggested by Porter, cost leadership is the strategy of a firm offering standardized products at very low per-unit costs for buyers who are price-sensitive; differentiation is the strategy of a firm offering products that are considered unique industry-wide and are addressed to buyers who are relatively price-insensitive [14].
} 
aim of feeding into the 2014-2020 programming cycle. Nevertheless, our findings seem coherent with those of authoritative sources in the field, such as the World Economic Forum's New Vision for Agriculture initiative [17]. We believe that the features shared by successful projects help shed light on what it takes for governmental incentives to promote effective partnerships in the agricultural sector. Thanks to a better understanding of these commonalities, policy-makers promoting rural development in the EU as well as in the Russian Federation can improve the cost-effectiveness of incentive schemes, in particular by setting tighter standards to be met by agricultural firms wishing to access preferential funding.

Research was conducted in the framework of and received partial funding by the Friuli Venezia Giulia Rural Development Programme for 2007-2013 of the European Agricultural Fund for Rural Development.

\section{REFERENCES}

1. Zeldner, A.G. State regulation in the agrarian sphere // Economics of agricultural and processing enterprises. - 1993. - №3. - pp. 3-7

2. Kiselev, S.V. State regulation of agriculture in the conditions of transition economy // Moscow: Institute of Economics, 1994. - pp. 179

3. Putin, V.V. To improve the efficiency of state agrarian policies // Agro-industrial system: economy, management. - 2008. - №7. - pp. 2-4

4. CAP Expenditure in the total EU expenditure [Electronic source]: https://ec.europa.eu/agriculture/sites/agriculture/files/cap-post2013/graphs/graph1_en.pdf

5. Chirkov, E. State support and regulation of agro-industrial production // Agro-industrial system: economy, management. - 1998. - №7. - pp. 15-22

6. Surovtseva, E.S. The grant mechanism of the state policy of the peasant (farmer) economies // Economics of agriculture of Russia. - 2016. - №10. - pp. 2-9

7. Polukhin, A. A. Main directions of reproduction of material and technical base of the rural agribusiness in Russia // Agro-industrial system: economy, management. - 2012. - №12. - pp. 57-63

8. Vargas-Lundius, R. The power of partnerships: forging alliances for sustainable smallholder agriculture // Rome: International Fund for Agricultural Development, 2013. pp. 12

9. Regione Autonoma Friuli Venezia Giulia, Direzione centrale attività produttive, commercio, cooperazione, risorse agricole e forestali, Servizio politiche rurali e sistemi informative in agricoltura. Rural development programme 2014-2020. - 2014. - pp. 930

10. Regione Autonoma Friuli Venezia Giulia, Direzione centrale risorse rurali, agroalimentari e forestali, Servizio sviluppo rurale. Rural development programme 2007-2013. - 2007. pp. 445

11. Stewart, J. Multiple-case study methods in governance-related research // Public Management Review. - 2012. - №14(1). - pp. 67-82

12. De Rosario, B. RUR@CT methodological guide: recommendations and tools for transferring good practices // Strasbourg: Assembly of European Regions, 2013. - pp. 38

13. Berdegué, J.A. et al. Keys to inclusion of small-scale producers in dynamic markets: innovative practice in connecting small-scale producers with dynamic markets. // London: International Institute for Environment and Development, 2008. - pp. 48

14. Porter, M. How competitive forces shape strategy // Harvard Business Review. - 1979. №57(2). - pp. 137-144

15. Kingdon, J.W. Agendas, alternatives and public policies // London: Longman, 1995. - pp. 254

16. Thaler, R., Sunstein, C. Nudge: improving decisions about health, wealth and happiness // New Haven: Yale University Press, 2008. - pp. 312

17. World Economic Forum. Building partnerships for sustainable agriculture and food security: a guide to country-led action // Geneva: World Economic Forum, 2016. - pp. 40 